\title{
Demonstration of velocity selective myocardial arterial spin labeling perfusion CMR
}

\author{
Terrence R Jao ${ }^{1 *}$, Krishna S Nayak ${ }^{2}$ \\ From 19th Annual SCMR Scientific Sessions \\ Los Angeles, CA, USA. 27-30 January 2016
}

\section{Background}

Arterial spin labeling of the heart has been shown to estimate myocardial perfusion and perfusion reserve at a single short-axis slice for coronary artery disease assessment. However, current spatial labeling methods suffer from transit delay effects when imaging is extended to more than a single slice. Velocity selective (VS) labeling is a promising alternative that does not suffer from transit delay effects.

\section{Methods}

Eight healthy volunteers were scanned using a 3T GE Signa Excite HD scanner with an 8-channel cardiac coil. Myocardial ASL measurements were made at a single short axis slice using both VSASL and conventional flow alternating inversion recovery (FAIR) ASL as a reference. VS labeling was performed using an adiabatic BIR4 pulse with bipolar gradients as shown in Figure 1A. Labeling was achieved by saturating all spins above a cutoff velocity of $10 \mathrm{~cm} / \mathrm{s}$ to target coronary blood velocity. Triple inversion recovery was used to suppress a range of myocardial T1s between $1250 \mathrm{~ms}$ and $1450 \mathrm{~ms}$ for background suppression. 6 breath-held labeled/control image pairs were acquired per subject. Myocardial blood flow (MBF), physiological noise (PN), and temporal SNR $(\mathrm{TSNR}=\mathrm{MBF} / \mathrm{PN})$ were measured within the left ventricular myocardium ROI.

\section{Results}

Figure 1B shows that the VS labeling pulse was successful in saturating blood within the coronary artery. MBF and PN measurements from VSASL and FAIR were $1.69 \pm$ $0.84 \mathrm{ml} / \mathrm{g} / \mathrm{min}$ and $2.22 \pm 0.57 \mathrm{ml} / \mathrm{g} / \mathrm{min}$ respectively in eight volunteers. This corresponds to a TSNR of 2.01 and 3.89 respectively. VSASL underestimated MBF by $23.8 \%$ when compared to FAIR, which may be due to a signal
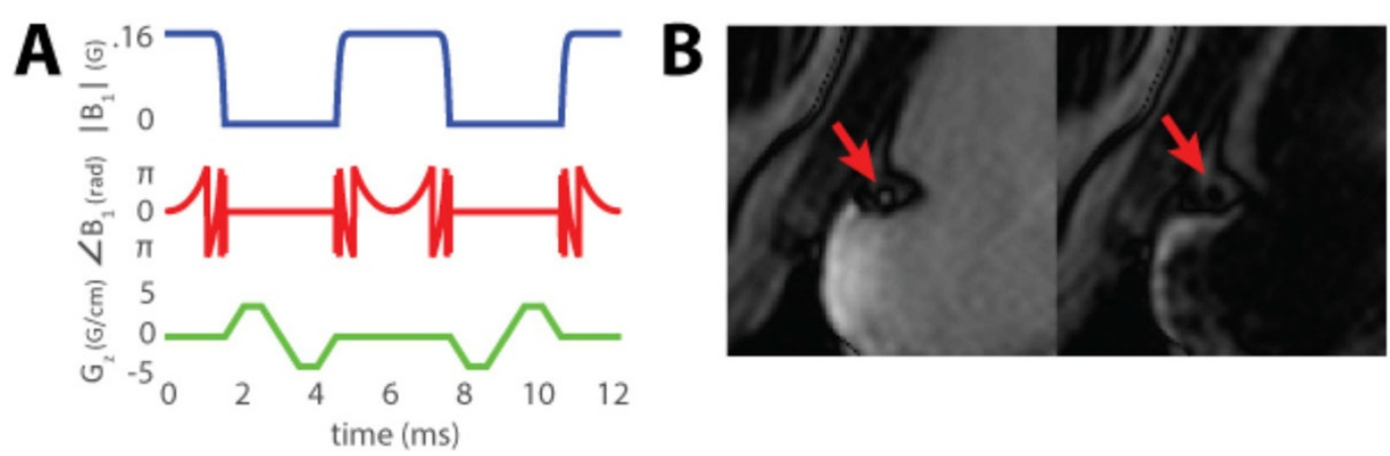

Figure $1 \mathrm{~A}$. the Velocity selective pulse is made using a symmetric BIR4 for reduced eddy current sensitivity and bipolar gradients to prevent spatial signal modulation in static tissue. B. Coronary arterial blood (red) is saturated by VS labeling at mid-diastole with a velocity cutoff of $10 \mathrm{~cm} / \mathrm{s}$. Left: Gz "off" ( $T_{2}$ weighting only) Right: Gz "on" ( $T_{2}$ weighting + velocity selective saturation).

${ }^{1}$ Biomedical Engineering, University of Southern California, Los Angeles, CA,

USA

Full list of author information is available at the end of the article 


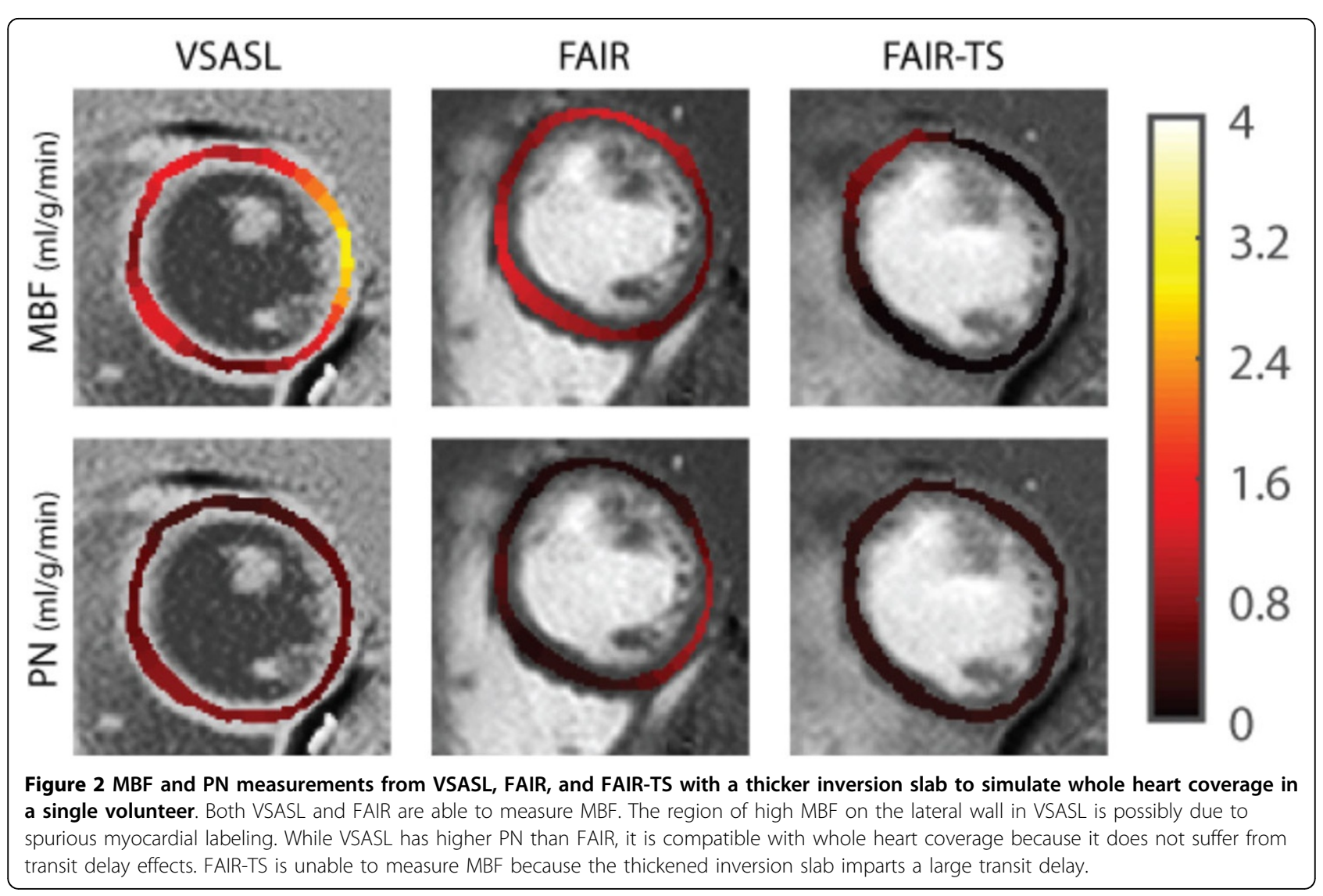

loss of 15\% from inversion inefficiency in background suppression combined with a T2 signal loss of 7\% from the $12 \mathrm{~ms}$ VS pulse. We suspect that higher PN in VSASL is from spurious labeling of myocardium, which can be further reduced by more consistent background suppression. Low TSNR will be addressed by further sequence improvements that explore different cutoff velocities and velocity labeling directions. In a single volunteer, we performed an additional FAIR experiment with a thicker inversion slab (FAIR-TS) to simulate whole heart coverage. MBF and PN measurements from VSASL, FAIR, and FAIR-TS were $1.38 \pm 0.58 \mathrm{ml} / \mathrm{g} / \mathrm{min}, 0.88 \pm 0.37 \mathrm{ml} / \mathrm{g} /$ $\mathrm{min}$, and $-0.04 \pm 0.24 \mathrm{ml} / \mathrm{g} / \mathrm{min}$ respectively. FAIR-TS has a large transit delay and is unable to estimate MBF while VSASL does not suffer from transit delay effects.

\section{Conclusions}

We have successfully labeled coronary blood based on velocity and demonstrated that VSASL is sensitive to myocardial perfusion. We believe that VSASL has the potential to become a more sensitive labeling scheme than spatial labeling sequences because of its insensitivity to transit delay and because it is inherently compatible with whole heart coverage.

\section{Authors' details}

'Biomedical Engineering, University of Southern California, Los Angeles, CA, USA. ${ }^{2}$ Electrical Engineering, University of Southern California, Los Angeles, CA, USA.

Published: 27 January 2016

doi:10.1186/1532-429X-18-S1-P98

Cite this article as: Jao and Nayak: Demonstration of velocity selective myocardial arterial spin labeling perfusion CMR. Journal of Cardiovascular Magnetic Resonance 2016 18(Suppl 1):P98.

\section{Submit your next manuscript to BioMed Central} and take full advantage of:

- Convenient online submission

- Thorough peer review

- No space constraints or color figure charges

- Immediate publication on acceptance

- Inclusion in PubMed, CAS, Scopus and Google Scholar

- Research which is freely available for redistribution 